\title{
A pediatric critical care perspective on vitamin D
}

\author{
Riad Abou-Zahrr ${ }^{1}$ and Sarah B. Kandil ${ }^{2}$
}

The mechanisms of action of vitamin $D$ are the subject of intense investigation. Evidence now suggests vitamin D affects immune function and cell proliferation, prompting interest in its role in critical illness and cardiac disease. Multiple studies demonstrate strong associations between vitamin D deficiency and severity of illness including need for higher inotrope support, more fluid resuscitation, and longer intensive care unit stay. The pediatric cardiac population may be at even more risk and nearly twice as likely to be deficient compared to the noncardiac population. Low vitamin D levels have been found in postoperative cardiac patients, where investigators speculate cardiopulmonary bypass alters levels directly or indirectly. Patients with congestive heart failure who are deficient also seem to benefit from vitamin D supplementation. This review summarizes recent studies in children that investigate the relation between vitamin $\mathrm{D}$ status and clinical outcomes in the critically ill including those with cardiac disease.

V itamin $\mathrm{D}$, its receptor, and its properties have recently become the subject of intense investigation. It is estimated that about one billion people around the world are vitamin $\mathrm{D}$ deficient or insufficient. There is no universal definition of vitamin D deficiency; however, the 2011 Institute of Medicine report considered 25 hydroxycholecalciferol 25(OH)D levels of $50 \mathrm{nmol} / \mathrm{l}$ to be sufficient in $97.5 \%$ of the population $(1,2)$. Levels less than $50 \mathrm{nmol} / \mathrm{l}$ are considered inadequate and reflect a state of deficiency. It has been long known that vitamin $\mathrm{D}$ deficiency causes rickets in children and osteomalacia in adults (2). Among healthy children and adolescents in the United States, the prevalence of deficiency is 9-18\% (3-5).

It is less clear what impact deficiency has on the critically ill. Among critically ill adults, prevalence rates are reported between 17 and $80 \%(6,7)$ whereas among critically ill children rates are $35-70 \%(8-10)$. There is increasing evidence that deficiency in critically ill populations is associated with increased mortality risk, longer stay in intensive care units and increased risk of infections $(6,7,11)$. While it is possible that vitamin D is itself a marker of illness, the presence of vitamin D receptors on tissues such as cardiomyocytes and immune cells that respond to the active form of vitamin D suggests it is more likely directly involved in the pathophysiology of illness and inflammation (12). This review focuses on what is currently known about vitamin D status in critically ill children including those with cardiac disease.

\section{VITAMIN D KINETICS}

The concentration of $25(\mathrm{OH}) \mathrm{D}$ in plasma is 1,000 -fold higher than that of $1 \alpha 25(\mathrm{OH})_{2} \mathrm{D}$, which is the metabolically active hormone (13). Because $25(\mathrm{OH}) \mathrm{D}$ has a much longer half-life $(15 \mathrm{~d})$ than $1 \alpha 25(\mathrm{OH})_{2} \mathrm{D}(15 \mathrm{~h})$, it is widely accepted that measurement of $25(\mathrm{OH}) \mathrm{D}$ provides the best reflection of vitamin D nutritional status (13-15).

Eighty-five to $90 \%$ of $25(\mathrm{OH}) \mathrm{D}$ in serum is bound to vitamin D binding protein (VDBP), while $10-15 \%$ is bound to albumin and less than $1 \%$ is free in plasma (16). Genetic polymorphisms in the VDBP genes have been described (17). These polymorphisms result in VDBP variants that have different affinities to $25(\mathrm{OH}) \mathrm{D}$ and vary with race $(18-20)$. Powe et al. even suggest that the bioavailable 25(OH)D (not bound to VDBP) may represent a better indicator of deficiency. However, their methodologies of measuring vitamin D and VDBP are not standardized (21).

\section{VITAMIN D RECEPTOR}

VDR has been isolated in as many as 30 tissues and cell types in humans including B and T lymphocytes, adipose tissues, muscle, and bone marrow (22). In mice, the VDR has even been isolated in t-tubules of cardiomyocytes (23). In their work, Tishkoff et al. showed that the acute rapid $(5 \mathrm{~min})$ effect of $1 \alpha 25(\mathrm{OH})_{2} \mathrm{D}$ on cardiomyocytes is to accelerate relaxation, which has implications in diastolic dysfunction (23). In addition, they demonstrated that VDR knock-out myocytes exhibited increased rates of contraction and relaxation which disturbed contractile kinetics. This suggests that vitamin D affects contractility directly through a mechanism that is independent of serum calcium though perhaps related to intracellular sarcoplasmic reticular calcium. Literature also suggests that vitamin $\mathrm{D}$ has anti-inflammatory properties, which may improve overall cardiovascular function $(24,25)$. The role of vitamin $\mathrm{D}$ in immune function and pediatric infections was previously reviewed by Walker and Modlin (26).

\section{VITAMIN D AND CRITICAL ILLNESS}

In 2009, Lee et al. were among the first to report a high prevalence of vitamin D deficiency among critically ill adults and 


\section{Vitamin D in critical illness}

furthermore demonstrated worse outcomes in those patients (27). Since then a number of adult studies have reported associations between vitamin D deficiency and worse outcomes, including mortality (7,27-31). Braun et al. demonstrated that critically ill patients who were vitamin $\mathrm{D}$ deficient had a 1.9 -fold increased risk of 30 -d mortality (95\% confidence interval $(\mathrm{CI})=1.15-2.98 ; P=0.01)$ compared to vitamin $\mathrm{D}$ sufficient patients. The authors also reported that deficiency was an independent predictor of mortality (7). Similar findings were reported by Amrein et al. in a single center review where critically ill patients with deficient 25(OH)D levels had a significantly higher risk of adjusted hospital mortality (hazard ratio of $2.05,95 \% \mathrm{CI}=1.331-3.22$ ) compared to sufficient patients. Currently, interventional studies are underway in adult critically ill deficient patients, including a large randomized controlled trial $(28,32,33)$. The results of which are eagerly awaited.

Within pediatric critical care vitamin D status is less studied. In our literature review, we searched PubMed, Ovid MEDLINE and ISI Web of Science for articles published within the last 10 y containing the terms "vitamin D and intensive care or critical care or critical illness." We limited the articles to "all child (0-18 years old)" and "English." We then reviewed the abstracts and full texts of all relevant articles. We obtained 62 articles from PubMed, 26 articles from Ovid MEDLINE and 16 articles from ISI Web of Science. Fifty-eight articles were excluded due to duplication or were irrelevant. Upon further review, there were only four studies that included data on epidemiology and outcomes of vitamin $\mathrm{D}$ adequacy in critically ill pediatric patients, which are reviewed here (Table 1) (8-10,34). Currently, there is one interventional phase II trial underway investigating vitamin $\mathrm{D}$ replacement in preoperative congenital heart disease patients (www.clinicaltrials.gov; NCT01838447). This review will highlight the recent studies among pediatric critically ill children.

Madden et al., conducted a prospective cohort study at Boston Children's Hospital pediatric intensive care unit (PICU) looking at vitamin D levels around the time of admission, though cardiac surgery patients were excluded (8). The authors found a significant association between $25(\mathrm{OH}) \mathrm{D}$ deficiency and worse clinical outcomes. Deficient patients had higher severity of illness scores and more likely to require vasopressor support. There was no association found between 25(OH)D levels and duration of mechanical ventilation. Interestingly, almost all patients had normal ionized serum calcium levels (8). The authors concluded that these findings are probably secondary to vitamin D's role in immune modulation, inflammation, and calcium homeostasis rather than hemodilution and fluid shifts.

Table 1 Summary of vitamin D studies in critically ill children

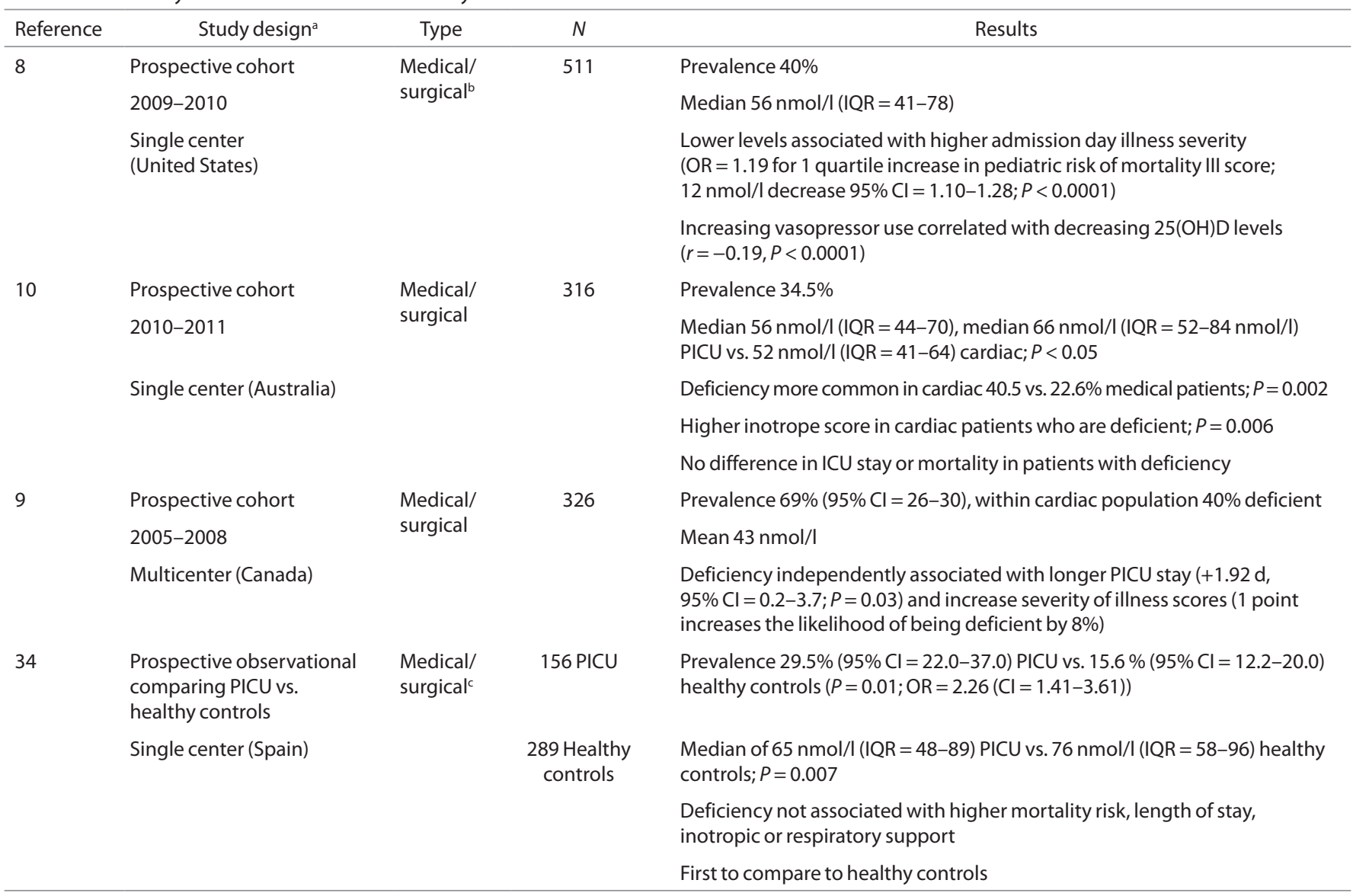


McNally et al. also showed worse outcomes in their multicentered study of critically ill children across Canada (9). Interestingly the mean $25(\mathrm{OH}) \mathrm{D}$ levels $(43 \mathrm{nmol} / \mathrm{l})$ were considerably lower than the mean level of $67-75 \mathrm{nmol} / \mathrm{l}$ reported among healthy Canadian and US children $(5,35)$. Lower $25(\mathrm{OH}) \mathrm{D}$ levels were found in patients who required catecholamine infusions, were hypocalcemic, received more than $40 \mathrm{ml} / \mathrm{kg}$ of fluid resuscitation and needed mechanical ventilation. Deficiency was also independently associated with an increase of $\sim 2 \mathrm{~d}$ stay in the PICU (9). The authors speculate that acute drops in vitamin $\mathrm{D}$ may be more physiologically significant than chronic deficiency because during critical illness compensatory mechanisms are affected by inflammation and multiorgan dysfunction. This same group is currently working on a phase II trial investigating vitamin D supplementation prior to cardiac surgery.

Somewhat different findings were observed by Rippel et al. in their study of critically ill children of which two thirds were postoperative cardiac patients (10). Contrary to other studies, no association was found between $25(\mathrm{OH}) \mathrm{D}$ deficiency and need for mechanical ventilation, vasoactive support, ICU or hospital length of stay, severity of illness scores or mortality. Of note, cardiac patients were nearly twice as likely to be deficient when compared to noncardiac patients (10).

Rey et al. is the most recent to investigate vitamin D deficiency within the PICU (34). In this study, vitamin D levels of critically ill children were compared with levels of healthy children within the same area of Spain. Despite the PICU patients having nearly twice the rate of deficiency compared to healthy controls, no difference in risk of mortality scores was found for deficient patients (34).

A limitation of the pediatric studies is that no preillness vitamin D levels were measured; therefore, it's uncertain whether lower levels are a result of illness, acute therapies, or represent a preillness chronic deficiency state. The discrepant results among these studies demonstrate the continued need for research to truly understand the role of vitamin D during critical illness. Interestingly, children who are postoperative from cardiac surgery seem to be an especially vulnerable population and further investigation into this specific population will need to be evaluated.

\section{VITAMIN D IN CARDIOPULMONARY BYPASS}

One hypothesis regarding why postoperative cardiac surgery patients had higher risk of vitamin D deficiency was the effects of cardiopulmonary bypass (CPB). In adults, CPB significantly lowered serum $25(\mathrm{OH}) \mathrm{D}$ levels in patients undergoing elective cardiac surgery $(36,37)$. This was thought to be a dilution effect secondary to volume expansion. However, in the pediatric population, there are conflicting reports. In neonates, undergoing cardiac surgery, CPB did not have any effect on $25(\mathrm{OH})$ $\mathrm{D}$ although $84 \%$ were deficient prior to surgery (38). More recently, McNally et al. showed a marked decline in 25(OH)D levels postoperatively in their single center prospective cohort study of children less than 18 y old undergoing cardiac surgery (39). Blood was collected at three time points: preoperatively, intraoperatively and postoperatively in a total of 54 patients who underwent $\mathrm{CPB}$. The mean $25(\mathrm{OH}) \mathrm{D}$ level before surgery was $60 \mathrm{nmol} / 1$ and $42 \%$ of patients were deficient. CPB resulted in a decrease of the mean to $35 \mathrm{nmol} / \mathrm{l}$ with $84 \%$ of patients deficient. Low postoperative $25(\mathrm{OH}) \mathrm{D}$ levels were also associated with increased catecholamine levels, fluid requirements, and longer duration of mechanical ventilation. Interestingly, there were low levels of $25(\mathrm{OH}) \mathrm{D}$ in the modified ultra-filtrate of the bypass circuit suggesting that a mechanism other than a simple dilution effect may be taking place (39). Future studies should also focus on VDBP fluctuations during $\mathrm{CPB}$ to gain better understanding of $25(\mathrm{OH}) \mathrm{D}$ status.

\section{VITAMIN D AND CONGESTIVE HEART FAILURE}

Beyond the acute setting, vitamin D's anti-inflammatory effects were reproduced in vivo in adults with congestive heart failure (40). In a randomized controlled trial among congestive heart failure patients, supplementation with vitamin D over 9 mo increased the anti-inflammatory cytokine interleukin 10 (IL-10) and prevented the rise of the proinflammatory marker tumor necrosis factor $\alpha$ (TNF- $\alpha$ ) (40). Although, vitamin D supplementation in adults with congestive heart failure did not improve physical performance as measured by peak oxygen consumption (41). In children, vitamin D supplementation was beneficial in treatment of congestive heart failure, as demonstrated by a recent double-blind placebo controlled study (42). Here, infants with congestive heart failure secondary to dilated cardiomyopathy or congenital heart disease with systemic left ventricular systolic dysfunction were randomized into vitamin D and placebo treatment groups (42). Both groups received anti-congestive heart failure therapy with digoxin, captopril, and spironolactone. Forty-two patients received 1,000 IU of Cholecalciferol oral drops (vitamin D group). Thirty-eight patients received placebo oral drops (placebo group). After $12 \mathrm{wk}$, there was a statistically significant increase in the anti-inflammatory cytokine IL-10 and decrease in the proinflammatory cytokines IL- 6 and TNF- $\alpha$ in the vitamin D group $(P<0.001)$. These changes were coupled with echocardiographic improvements in left ventricular dimensions and systolic function indices. Comparatively, there was some improvement in systolic function indices in the placebo group, but no improvement in IL-6, IL-10, or TNF- $\alpha$ (42). Should these findings become reproducible, vitamin D supplementation may become an adjunct in treatment of pediatric congestive heart failure.

\section{FUTURE DIRECTIONS}

In summary, it is unclear if vitamin D deficiency plays a role in pediatric critical illness and cardiac disease. While pediatric studies report lower vitamin D levels in critical illness, results are contrary if deficiency is associated with severity of illness or other clinical outcome measures. The cardiac population is especially vulnerable and twice as likely to be deficient. This has prompted investigation into the potential effects of cardiopulmonary bypass on vitamin D status as well as supplementation in those with heart failure. Studies thus far have been small and 
warrant further investigation. The next step should be interventional studies that target critically ill-25(OH)D deficient children with vitamin $\mathrm{D}$ supplementation to address whether there are improvements in clinical outcomes such as severity of disease, need for organ support or duration of stay. Potential studies should also focus on how best to supplement vitamin D during critical illness as this has yet to be determined.

Disclosure: The authors declare no conflict of interest.

\section{REFERENCES}

1. Ross AC, Manson JE, Abrams SA, et al. The 2011 report on dietary reference intakes for calcium and vitamin D from the Institute of Medicine: what clinicians need to know. J Clin Endocrinol Metab 2011;96:53-8.

2. Holick MF. Vitamin D deficiency. N Engl J Med 2007;357:266-81.

3. Kumar J, Muntner P, Kaskel FJ, Hailpern SM, Melamed ML. Prevalence and associations of 25-hydroxyvitamin D deficiency in US children: NHANES 2001-2004. Pediatrics 2009;124:e362-70.

4. Karalius VP, Zinn D, Wu J, et al. Prevalence of risk of deficiency and inadequacy of 25-hydroxyvitamin D in US children: NHANES 2003-2006. J Pediatr Endocrinol Metab 2014;27:461-6.

5. Mansbach JM, Ginde AA, Camargo CA Jr. Serum 25-hydroxyvitamin D levels among US children aged 1 to 11 years: do children need more vitamin D? Pediatrics 2009;124:1404-10.

6. Venkatram S, Chilimuri S, Adrish M, Salako A, Patel M, Diaz-Fuentes G. Vitamin D deficiency is associated with mortality in the medical intensive care unit. Crit Care 2011;15:R292.

7. Braun AB, Gibbons FK, Litonjua AA, Giovannucci E, Christopher KB. Low serum 25-hydroxyvitamin $\mathrm{D}$ at critical care initiation is associated with increased mortality. Crit Care Med 2012;40:63-72.

8. Madden K, Feldman HA, Smith EM, et al. Vitamin D deficiency in critically ill children. Pediatrics 2012;130:421-8.

9. McNally JD, Menon K, Chakraborty P, et al.; Canadian Critical Care Trials Group. The association of vitamin D status with pediatric critical illness. Pediatrics 2012;130:429-36.

10. Rippel C, South M, Butt WW, Shekerdemian LS. Vitamin D status in critically ill children. Intensive Care Med 2012;38:2055-62.

11. Higgins DM, Wischmeyer PE, Queensland KM, Sillau SH, Sufit AJ, Heyland DK. Relationship of vitamin D deficiency to clinical outcomes in critically ill patients. JPEN J Parenter Enteral Nutr 2012;36:713-20.

12. Amrein K, Venkatesh B. Vitamin D and the critically ill patient. Curr Opin Clin Nutr Metab Care 2012;15:188-93.

13. Heaney RP, Barger-Lux MJ, Dowell MS, Chen TC, Holick MF. Calcium absorptive effects of vitamin D and its major metabolites. J Clin Endocrinol Metab 1997;82:4111-6.

14. Parfitt AM, Gallagher JC, Heaney RP, Johnston CC, Neer R, Whedon GD. Vitamin D and bone health in the elderly. Am J Clin Nutr 1982;36:Suppl 5:1014-31.

15. Jones G. Pharmacokinetics of vitamin D toxicity. Am J Clin Nutr 2008;88:582S-6S.

16. Bikle DD, Gee E, Halloran B, Kowalski MA, Ryzen E, Haddad JG. Assessment of the free fraction of 25-hydroxyvitamin D in serum and its regulation by albumin and the vitamin D-binding protein. J Clin Endocrinol Metab 1986;63:954-9.

17. Engelman CD, Fingerlin TE, Langefeld CD, et al. Genetic and environmental determinants of 25-hydroxyvitamin $\mathrm{D}$ and 1,25-dihydroxyvitamin D levels in Hispanic and African Americans. J Clin Endocrinol Metab 2008;93:3381-8.

18. Arnaud J, Constans J. Affinity differences for vitamin D metabolites associated with the genetic isoforms of the human serum carrier protein (DBP). Hum Genet 1993;92:183-8.

19. Powe CE, Evans MK, Wenger J, et al. Vitamin D-binding protein and vitamin D status of black Americans and white Americans. N Engl J Med 2013;369:1991-2000.

20. Constans J, Hazout S, Garruto RM, Gajdusek DC, Spees EK. Population distribution of the human vitamin D binding protein: anthropological considerations. Am J Phys Anthropol 1985;68:107-22.
21. Bouillon R, Jones K, Schoenmakers I. Vitamin D-binding protein and vitamin D in blacks and whites. N Engl J Med 2014;370:879.

22. Norman AW. Minireview: vitamin D receptor: new assignments for an already busy receptor. Endocrinology 2006;147:5542-8.

23. Tishkoff DX, Nibbelink KA, Holmberg KH, Dandu L, Simpson RU. Functional vitamin D receptor (VDR) in the t-tubules of cardiac myocytes: VDR knockout cardiomyocyte contractility. Endocrinology 2008;149:558-64.

24. Zhu Y, Mahon BD, Froicu M, Cantorna MT. Calcium and 1 alpha,25-dihydroxyvitamin D3 target the TNF-alpha pathway to suppress experimental inflammatory bowel disease. Eur J Immunol 2005;35:217-24.

25. Canning MO, Grotenhuis K, de Wit H, Ruwhof C, Drexhage HA. 1-alpha,25-Dihydroxyvitamin D3 $(1,25(\mathrm{OH})(2) \mathrm{D}(3))$ hampers the maturation of fully active immature dendritic cells from monocytes. Eur J Endocrinol 2001;145:351-7.

26. Walker VP, Modlin RL. The vitamin D connection to pediatric infections and immune function. Pediatr Res 2009;65(5 Pt 2):106R-13R.

27. Lee P, Eisman JA, Center JR. Vitamin D deficiency in critically ill patients. N Engl J Med 2009;360:1912-4.

28. Mata-Granados JM, Vargas-Vasserot J, Ferreiro-Vera C, Luque de Castro MD, Pavón RG, Quesada Gómez JM. Evaluation of vitamin D endocrine system (VDES) status and response to treatment of patients in intensive care units (ICUs) using an on-line SPE-LC-MS/MS method. J Steroid Biochem Mol Biol 2010;121:452-5.

29. Lucidarme O, Messai E, Mazzoni T, Arcade M, du Cheyron D. Incidence and risk factors of vitamin $\mathrm{D}$ deficiency in critically ill patients: results from a prospective observational study. Intensive Care Med 2010;36:1609-11.

30. McKinney JD, Bailey BA, Garrett LH, Peiris P, Manning T, Peiris AN. Relationship between vitamin D status and ICU outcomes in veterans. J Am Med Dir Assoc 2011;12:208-11.

31. Amrein K, Zajic P, Schnedl C, et al. Vitamin D status and its association with season, hospital and sepsis mortality in critical illness. Crit Care 2014; $18:$ R47.

32. Amrein K, Sourij H, Wagner G, et al. Short-term effects of high-dose oral vitamin D3 in critically ill vitamin D deficient patients: a randomized, double-blind, placebo-controlled pilot study. Crit Care 2011;15:R104.

33. Amrein K, Schnedl C, Berghold A, Pieber TR, Dobnig H. Correction of vitamin D deficiency in critically ill patients - VITdAL@ICU study protocol of a double-blind, placebo-controlled randomized clinical trial. BMC Endocr Disord 2012;12:27.

34. Rey C, Sánchez-Arango D, López-Herce J, et al. Vitamin D deficiency at pediatric intensive care admission. J Pediatr (Rio J) 2014;90:135-42.

35. Langlois K, Greene-Finestone L, Little J, Hidiroglou N, Whiting S. Vitamin D status of Canadians as measured in the 2007 to 2009 Canadian Health Measures Survey. Health Rep 2010;21:47-55.

36. Zittermann A, Schleithoff SS, Götting C, et al. Calcitriol deficiency and 1-year mortality in cardiac transplant recipients. Transplantation 2009;87:118-24.

37. Krishnan A, Ochola J, Mundy J, et al. Acute fluid shifts influence the assessment of serum vitamin D status in critically ill patients. Crit Care 2010;14:R216.

38. Graham EM, Taylor SN, Zyblewski SC, et al. Vitamin D status in neonates undergoing cardiac operations: relationship to cardiopulmonary bypass and association with outcomes. J Pediatr 2013;162:823-6.

39. McNally JD, Menon K, Chakraborty P, et al. Impact of anesthesia and surgery for congenital heart disease on the vitamin $\mathrm{d}$ status of infants and children: a prospective longitudinal study. Anesthesiology 2013;119:71-80.

40. Schleithoff SS, Zittermann A, Tenderich G, Berthold HK, Stehle P, Koerfer R. Vitamin D supplementation improves cytokine profiles in patients with congestive heart failure: a double-blind, randomized, placebo-controlled trial. Am J Clin Nutr 2006;83:754-9.

41. Boxer RS, Kenny AM, Schmotzer BJ, Vest M, Fiutem JJ, Piña IL. A randomized controlled trial of high dose vitamin D3 in patients with heart failure. JACC Heart Fail 2013;1:84-90.

42. Shedeed SA. Vitamin D supplementation in infants with chronic congestive heart failure. Pediatr Cardiol 2012;33:713-9. 